\title{
Coping-Related Variables Associated with Individual Differences in Adjustment to Cancer
}

Jeremy P. Shapiro

Tanujit Dey

William \& Mary, tdey@wm.edu

Harold S. Haller

Follow this and additional works at: https://scholarworks.wm.edu/aspubs

\section{Recommended Citation}

Shapiro, J. P., McCue, K., Heyman, E. N., Dey, T., \& Haller, H. S. (2010). Coping-related variables associated with individual differences in adjustment to cancer. Journal of Psychosocial Oncology, 28(1), 1-22.

This Article is brought to you for free and open access by the Arts and Sciences at W\&M ScholarWorks. It has been accepted for inclusion in Arts \& Sciences Articles by an authorized administrator of W\&M ScholarWorks. For more information, please contact scholarworks@wm.edu. 


\title{
Coping-Related Variables Associated with Individual Differences in Adjustment to Cancer
}

\author{
JEREMY P. SHAPIRO, PhD \\ Psychological and Behavioral Consultants, Cleveland, OH, USA
}

KATHLEEN MCCUE, MA, LSW, CCLS and ELLEN N. HEYMAN, MSN, RN, CS

The Gathering Place, Beachwood, OH, USA

TANUJIT DEY, PhD

Department of Mathematics, The College of William and Mary, Williamsburg, VA, USA

HAROLD S. HALLER, PhD

Case Statistical Consulting Service, Case Western Reserve University, Cleveland, OH, USA

This study examined relationships between emotional adjustment and a number of coping styles and strategies in people with cancer. Two-bundred eighty-three adults completed measures of positive and negative emotions, subjective ratings of cancer-related symptoms and functional impairment, coping strategies, bope, benefit finding, emotional approach/avoidance, and cancer-related social support. Among the coping strategies, self-blame and behavioral disengagement were consistently associated with poor adjustment, while acceptance and bumor were consistently associated with good adjustment. Among the broader measures of coping style, there were associations between poor adjustment and emotional processing, and between good adjustment and bope, benefit finding, and cancer-related social support.

KEYWORDS cancer, adjustment, coping

People with cancer exhibit a wide range of emotional functioning. Most patients adapt fairly well, but a significant minority experience serious distress in response to the illness (Glanz \& Lerman, 1998; Lethborg, Aranda,

This research was supported by Grant \#2005059 from the Saint Lukes Foundation.

Address correspondence to Jeremy P. Shapiro, PhD, 2669 Belvoir Blvd., Shaker Heights, OH 44122. E-mail: Jeremyshapiro@Yahoo.com 
Cox, \& Kissane, 2007). Developing an understanding of the variables that account for individual differences in adjustment to cancer is an important scientific goal. Such an understanding would facilitate the design of interventions to help patients manage the emotional consequences of this illness.

Studies of the prevalence of psychological distress in cancer patients have produced variable results. A number of studies have found rates of clinically significant distress in the 30\% to 40\% range (Carlson et al., 2004; Schag, Ganz, Wing, Sim, \& Lee, 1994; Zabora et al., 2001). Research on cancer patients has documented elevated rates of anxiety (Osowiecki \& Compas, 1998) and depression (Ciaramella \& Poli, 2001); Mermelstein and Lesko (1992) found a 4 times greater incidence of depression in these patients, compared to the general population. However, some investigations have found rates of depression and anxiety similar to those in nonpatient populations (Bardwell et al., 2006; Komblith et al., 2007). Other studies have found intermediate rates of disturbance.

Cancer does not take its psychological toll only by increasing levels of negative emotion; it also reduces positive affective experience. General psychological research has found that positive and negative emotions are distinct dimensions of experience that vary quite independently of each other (Watson, Clark, \& Tellegen, 1988; Zelenski \& Larsen, 1999). In research on cancer, Voogt et al. (2005) found that, compared to population norms, patients did not show high levels of negative affect, but they did exhibit low levels of positive affect.

Efforts to explain individual differences in adjustment to cancer have examined three broad classes of variables: demographic, medical, and psychosocial. A narrative review by Mosher and Danoff-Burg (2005) and a metaanalysis by van't Spijker, Trijsburg, and Duivenvoorden (1997) indicated that younger patients tend to be more distressed than older ones, although there have also been studies finding no age effects (Osborne, Elsworth, \& Hopper, 2003; Schnoll, Knowles, \& Harlow, 2002). Results for sex differences have not been consistent; for example, Parker, Baile, De Moore, and Cohen (2003) found better adjustment in men, whereas Schnoll et al. (2002) found better adjustment in women. Most investigations of socioeconomic status and cancer have found less distress in patients with high levels of income and education (Carver \& Antoni, 2004; Osborne et al., 2003; Parker et al., 2003; Schnoll et al., 2002), but there have been exceptions (e.g., Helgeson, Cohen, Schulz, \& Yasko, 2000).

Objective characteristics of disease and medical treatment have not proved to be reliable predictors of psychosocial outcomes. Some studies have found greater adjustment difficulties in patients with advanced, severe cancer (Kugaya, Akechi, Okamura, Mikami, \& Uchitomi, 1999; Waldemann, Fritzkuleit, Raspe, \& Katalinic, 2007), but other studies have not found such an association (Carver et al., 2005; Epping-Jordan et al., 1999; Parker et al., 2003). In many studies, type and stage of cancer were unrelated to 
psychosocial adjustment (Gall, Miguez de Renart, \& Boonstra, 2000; Parker et al., 2003; Schnoll et al., 2002). Medical treatment and side effects were related to psychosocial outcomes in a study by Rodrigue, Behen, and Tumlin (1994) but not in a study by Bardwell et al. (2006). Even cancer recurrence has failed to predict adjustment difficulties in some studies (Carver et al., 2005; Parker et al., 2003). In contrast to objective medical variables, patients' subjective ratings of their physical symptoms and functioning have consistently predicted their psychosocial adjustment (Lethborg et al., 2007; Manne, Glassman, \& Du Hamel, 2001; and see meta-analysis by van't Spijker et al., 1997).

Among psychosocial variables, past research suggests that social support is probably the most consistent predictor of adjustment. Many studies have found that cancer patients with high levels of support experience less distress and more well-being, compared to those without much support (Crothers, Tomter, \& Garske, 2005; Helgeson, Snyder, \& Seltman, 2004; Schnoll et al., 2002). Strong social support also predicts lower cortisol levels, indicating lower levels of physiological distress (Chan et al., 2006).

Research on internal, psychological predictors of adaptation to cancer has placed considerable emphasis on coping styles and strategies. This research has practical implications for cancer patients and their clinicians because, if we could identify more and less effective coping strategies, we could help patients gear their coping efforts accordingly. Hack and Degner (2004) found that coping responses measured soon after cancer diagnosis predicted adjustment 3 years later.

However, research on coping and cancer has not produced a clear pattern of findings. A meta-analytic review by Roesch et al. (2005) found that this research has produced mixed, inconsistent results, and effect sizes have often been small. Roesch et al.'s review and van't Spijker et al.'s (1997) metaanalysis made the general finding that active problem-solving contributes to positive adjustment, whereas avoidant coping mechanisms are associated with dysfunction (Lutgendorf et al., 2002; McGovern, Heyman, \& Resnick, 2002; Schnoll et al., 2002). However, the effectiveness of approach-oriented versus avoidant coping styles seems to interact with contextual factors, including the severity of the patient's cancer (Costanzo, Lutgendorf, Rothrock, \& Anderson, 2006), and whether adjustment was measured a short or long time after diagnosis (Stanton, Danoff-Burg, \& Huggins, 2002). There is evidence that coping through emotional self-expression is associated with successful adjustment (Stanton, Kirk, Cameron, \& Danoff-Burg, 2000), although this effect seems to depend on gender, stress level, and whether the individual has an audience receptive to his or her expression of emotion (Low, Stanton, Thompson, Kwan, \& Ganz, 2006; Stanton et al., 2000). ThuneBoyle, Stygall, Keshtgar, and Newman (2005) reviewed 17 studies on religion and coping in cancer patients; they identified seven studies in which religious coping was associated with positive adaptation, seven in which no 
association was found, and three studies in which religious coping was associated with increased distress.

Focusing on positive versus negative aspects of experience is a broad aspect of coping style that has been extensively studied in cancer patients. This adaptational style takes several forms. Optimism, as a personality trait, predicts positive adjustment generally and, specifically, in people with cancer (Carver et al., 1993; Carver et al., 2005; Epping-Jordan et al., 1999). High levels of hope predict more effective coping and enhanced well-being in spinal cord injury and burn patients (Barnum, Snyder, Rapoff, Mani, \& Thompson, 1998; Elliott, Witty, Herrick, \& Hoffman, 1991). However, in a study of cancer patients by Stanton et al. (2002), hope did not have a direct effect on adjustment, although it interacted with coping-related variables to predict adjustment.

Benefit finding is a surprisingly common response to cancer that, in several studies, has predicted good adjustment, especially in the long term (Antoni et al., 2001; Carver \& Antoni, 2004; Shapiro et al., 2001; Tartaro et al., 2005). However, results in this area have been inconsistent, with results varying as a function of the specific measure of distress used in the study (Lechner, Carver, Antoni, Weaver, \& Phillips, 2006; Sears, Stanton, \& Danoff-Burg, 2003), and with one investigation (Tomich \& Helgeson, 2004) documenting an association between benefit finding and poor adjustment. A meta-analysis by Helgeson, Reynolds, and Tomich (2006), which examined studies of medical (not exclusively cancer) patients, found that benefit finding was associated with less depression and more positive well-being but was not related to anxiety, global distress, or quality of life.

\section{METHODS}

\section{Participants}

The study took place at a nonprofit organization that provides a wide variety of nonmedical services to people with cancer and their families. This community organization is located in a midwestern, metropolitan area, is not affiliated with any hospital or university, and offers services free of charge. Participants choose from among support groups, individual counseling, educational offerings, exercise programs, recreational activities, massage, and so forth.

Because the sample consisted entirely of individuals who sought services to help them with their cancer experience, it might not be representative of the general population of cancer patients. However, this sample might also have distinctive practical importance because they represent the subpopulation of cancer patients who seek psychosocial services from providers.

All adults with cancer who began receiving services at the organization during the period of data collection were considered potentially eligible 
for the study. There were 395 such individuals. In 15 cases, staff members believed the person was either too medically ill, emotionally distressed, or cognitively impaired to be able to complete the measures, and these individuals were considered ineligible for the study. Of the 380 persons whom we invited to participate, 26 declined. Three-hundred and fifty-four people agreed to participate and were given a battery of measures, which they took home to complete. Seventy-one people never returned the questionnaires, despite receiving three reminder phone calls. In summary, of the 380 people we invited to participate in the study, 283 returned their battery of measures, resulting in a response rate of $74 \%$.

Attrition analyses. We conducted attrition analyses to determine whether there were differences between organization attendees who did and did not complete the measures. We used the Two-Sample KolmogorovSmirnov Test to examine differences between these two groups in the demographic and medical information that were collected from all attendees when they first came to the organization. For age, the Kolmogorov-Smirnov Test Statistic $(K S)$ was $.130, p=.15$; for gender, $K S=.039, p=.99$; for ethnic group (classified as White vs. African American), $K S=.068, p=.92$; for education, $K S=.022, p=1.0$; for type of cancer (classified as breast cancer vs. all other types), $K S=.152, p=.09$; for time since diagnosis, $\mathrm{KS}=.036, p=1.0$; and for cancer recurrence, $K S=.057, p=.99$. Thus, there were no significant differences on any of these demographic and medical variables, which suggests that the research participants were a representative sample of people who received services at the organization.

The average age of our participants was 54.6 years old $(S D=11.7)$. Seventy-eight percent of the sample was female. Ethnic composition was 79\% White, 19\% African American, 2\% Hispanic, and there was one Asian participant. In regard to education, 1\% did not finish high school, 19\% completed high school, 27\% had some college education, 32\% had bachelor degrees, 20\% had master's degrees, and 2\% had doctoral degrees.

Forty-two percent of the participants had breast cancer, $8 \%$ lung cancer, 7\% colon, 6\% lymphoma, 5\% prostate, 5\% leukemia, 4\% ovarian, 4\% myeloma, 2\% pancreatic, and 17\% widely dispersed among a number of other types of cancer. We asked participants about their stage of cancer, but many did not know this information, and there was too much missing data on this item for reliable estimation. The average year of cancer diagnosis was 2004.04 ( $S D=4.70$ ); these data were collected in 2006. Fourteen percent of the participants had experienced a recurrence of cancer.

\section{Measures}

Our description of measures is organized in accordance with the way we conceptualized the data produced by these instruments. First, we present our measures of emotional outcomes, which we viewed as dependent variables. 
TABLE 1 Descriptive Statistics for the Primary Variables

\begin{tabular}{|c|c|c|c|c|c|}
\hline Variable & $M(S D)$ & Range & Variable & $M(S D)$ & Range \\
\hline Anxiety & $8.11(4.62)$ & $0-21$ & Brief COPE & & \\
\hline Depression & $5.39(4.00)$ & $0-21$ & Active coping & $4.14(1.52)$ & $0-6$ \\
\hline Positive affect & $9.47(2.87)$ & $0-12$ & Denial & $1.20(1.50)$ & $0-6$ \\
\hline Happiness & $6.04(2.38)$ & $0-10$ & Substance use & $0.44(1.12)$ & $0-6$ \\
\hline Social support & $9.10(2.80)$ & $0-12$ & Emotional support & $4.76(1.49)$ & $0-6$ \\
\hline Hope & $17.66(4.07)$ & $1-24$ & $\begin{array}{l}\text { Behavioral } \\
\text { disengagement }\end{array}$ & $0.56(1.06)$ & $0-6$ \\
\hline Benefit finding & $16.42(5.28)$ & $3-24$ & Venting & $2.28(1.53)$ & $0-6$ \\
\hline $\begin{array}{l}\text { Emotional } \\
\text { processing }\end{array}$ & $6.95(3.08)$ & $0-12$ & Instrumental support & $3.64(1.60)$ & $0-6$ \\
\hline $\begin{array}{l}\text { Emotional } \\
\text { expression }\end{array}$ & $7.81(2.73)$ & $0-12$ & Positive reframing & $3.31(1.84)$ & $0-6$ \\
\hline QLQ-C30 & & & Self-blame & $1.38(1.61)$ & $0-6$ \\
\hline $\begin{array}{l}\text { Emotional } \\
\text { functioning }\end{array}$ & $56.81(24.45)$ & $0-100$ & Planning & $3.90(1.74)$ & $0-6$ \\
\hline $\begin{array}{l}\text { Physical } \\
\text { functioning }\end{array}$ & $72.74(25.67)$ & $0-100$ & Humor & $1.91(1.74)$ & $0-6$ \\
\hline Role functioning & $65.32(37.12)$ & $0-100$ & Acceptance & $4.57(1.38)$ & $0-6$ \\
\hline $\begin{array}{l}\text { Cognitive } \\
\text { functioning }\end{array}$ & $68.00(26.21)$ & $0-100$ & Religion & $3.80(2.13)$ & $0-6$ \\
\hline $\begin{array}{l}\text { Social } \\
\text { functioning }\end{array}$ & $64.88(29.34)$ & $0-100$ & Self-distraction & $3.49(1.58)$ & $0-6$ \\
\hline
\end{tabular}

QLQ-C30 = Quality of Life Questionnaire.

Then, we present our measures for variables that might predict or influence emotional outcomes. Descriptive data for the measures is presented in Table 1.

Hospital Anxiety and Depression Scale (HADS). The HADS (Zigmond \& Snaith, 1983) is a 14-item instrument that was developed for patients with physical illnesses. There are seven items each in the Anxiety and Depression scales. Bjelland, Dahl, Haug, and Neckelmann (2002) reviewed extensive evidence for the reliability and validity of the HADS. The instrument has been used in a number of studies with cancer patients, and it has demonstrated a stable factor structure and high reliability (see Herrmann, 1997, for a review). In our sample, $\alpha=.88$ for the Anxiety scale, and $\alpha=.85$ for the Depression scale, both of which indicate satisfactory internal consistency.

The HADS was designed to be a measure of psychiatric disturbance, and score ranges have verbal descriptions indicating the likelihood of such disturbance: $0-7$ is considered normal; 8-10 indicates possible morbidity; and 11-21 indicates probable morbidity. These ranges provide a context for interpreting our sample's mean Anxiety score of 8.11, with a $S D$ of 4.62, and mean Depression score of 5.39 (4.00).

Center for Epidemiological Studies Depression Scale (CES-D) positive affect items. We measured positive affect by means of four selected items from the CES-D (Radloff, 1977). The CES-D is a reliable, valid measure of 
depression that has been used in many studies of cancer patients (Hann, Winter, \& Jacobsen, 1999). We selected items that tapped positive experiences (e.g., hopefulness) known to be at low levels in depression. In our sample, $\alpha=.88$ for this measure of positive affect, indicating satisfactory internal reliability.

Fordyce Emotions Questionnaire. We used a single-item measure of happiness from the Fordyce Emotions Questionnaire (Fordyce, 1988). This item asks respondents to rate their typical level of happiness on an 11point scale. Each of the points is defined by a clear verbal anchor, with additional elaboration provided in parentheses. For example, $0=$ extremely unhappy (utterly depressed, completely down), and $10=$ extremely happy (feeling ecstatic, joyous, fantastic). Fordyce (1988) documented the validity of this brief measure.

Quality of Life Questionnaire (QLQ-C30). We measured health-related quality of life with the European Organization for Research and Treatment of Cancer's QLQ-C30 (Aaronson et al., 1993), an instrument with wellestablished reliability and validity (Kart \& Ford, 2002). The QLQ-C30 was developed specifically for cancer patients. There are five Functioning scales. The Emotional Functioning Scale, which has four items, assesses anxiety, depression and irritability (e.g., "Did you feel tense?"). The Physical Functioning Scale, which has five items, asks whether the patient has had trouble walking, dressing, and performing other activities of daily living. There are two items each in the Role Functioning Scale (e.g., "Have you been limited in any way in doing either your work or household jobs?"), the Cognitive Functioning Scale (e.g., "Have you had difficulty remembering things?"), and the Social Functioning Scale (e.g., "Has your physical condition or medical treatment interfered with your family life?"). The QLQ-C30 also has three Symptom scales (Fatigue, Pain, and Nausea/Vomiting), and six single items that assess problems often associated with cancer and the side effects of its treatment (dyspnea, sleep disturbance, appetite loss, constipation, diarrhea, and financial difficulties).

We calculated Cronbach's alpha for the instrument's largest scales and found that, for Emotional Functioning, $\alpha=.74$, indicating acceptable internal consistency, but for Physical Functioning, $\alpha=.64$, which is below an acceptable level. The latter finding was unexpected because the QLQ-C30 is a widely used instrument that generally exhibits strong psychometric qualities. In our analyses, however, Physical Functioning scores should be viewed as a collection of somewhat heterogenous items related to physical capabilities, rather than as a reliable measure of one unified construct.

Social receptivity. To assess cancer-related social support, we used Stanton et al.'s (2000) measure of cancer patients' perception of how receptive the members of their social networks are to talking about cancer and its associated experiences. The instrument has three items (e.g., "There are people I can count on whenever I want to talk about my experience with cancer"). 
Items are rated on a 5-point scale that indicates degree of disagreement or agreement. In Stanton et al.'s study, the measure exhibited adequate internal consistency and test-retest reliability. In our sample, $\alpha=.86$, indicating a satisfactory level of internal consistency.

Brief COPE Inventory. The Brief COPE (Carver, 1997) is an abbreviated version of the COPE Inventory (Carver, Scheier, \& Weintraub, 1989). The instrument efficiently measures 14 coping mechanisms with 28 items (two items for each coping process). Responses are scored on a 4-point scale that indicates how much the respondent has used the coping strategy depicted by the item. The COPE assesses some strategies that, in past research on coping, have been found to be adaptive (active coping, use of emotional support, use of instrumental support, positive reframing, planning, humor, acceptance, and religion), and some strategies that have been found to be maladaptive (self-distraction, denial, substance use, behavioral disengagement, venting, and self-blame). Reliability coefficients for the 14 subscales range from .50 to .90 and, because the Brief COPE was developed on the basis of item reduction procedures, it probably shares in the validity previously established for the longer measure (Carver, 1997). In our procedure, the directions asked respondents to indicate their use of each coping strategy specifically in regard to the stressor of cancer.

Emotional Approach Coping Scales. This instrument by Stanton et al. (2000) assesses respondents' preference for approaching versus avoiding emotions as they cope with stress. There are two scales, each with four items. The Emotional Processing Scale measures introspective thinking about emotions (e.g., "I delve into my feelings to get a thorough understanding of them"), and the Emotional Expression Scale pertains to behavior with other people (e.g., "I feel free to express my emotions"). Both scales have demonstrated strong internal consistency and predictive validity (Stanton et al., 2000). In our sample, $\alpha=.86$ for Emotional Processing, and $\alpha=.93$ for Emotional Expression, indicating satisfactory degrees of internal reliability for both measures.

Hope. The Hope Scale (Snyder et al., 1991) assesses optimism about achieving goals. There are two subscales, each with four items. The Pathways subscale measures confidence in one's ability to think of ways to overcome obstacles and achieve goals (e.g., "I can think of many ways to get the things in life that are most important to me"). The Agency subscale assesses the belief that one is personally able to perform the actions necessary for goal attainment ("I meet the goals that I set for myself"). Snyder et al. (1991) demonstrated the scale's satisfactory reliability and its convergent, discriminant, and predictive validities. In our sample, $\alpha=.87$ for the Pathways subscale, $\alpha=.82$ for the Agency subscale, and $\alpha=.90$ for the entire Hope Scale, indicating satisfactory internal consistency.

Benefit finding. We constructed a brief measure of benefit finding that was geared to the experiences of people with cancer. There were eight 
items with content that was generally similar to items used in past studies of benefit finding (Antoni et al., 2001; Carver \& Antoni, 2004; Lechner et al., 2006; Sears et al., 2003; Tartaro et al., 2005). Examples included, "I have become more aware of how much other people care about me," and "I have become a stronger person." In the present sample, $\alpha=.86$, indicating satisfactory internal consistency.

\section{Procedure}

Participants were recruited for the study following their introductory tour of the facility, which included a description of available services. Potential participants were informed that enrollment in the study was voluntary and their decision whether to take part would have no effect on the services they received. Individuals who agreed to participate were given a set of questionnaires to complete.

\section{Data Analysis Plan}

The primary statistical procedure used in our analyses was a step-wise multiple regression method called "forward selection with review" (Draper \& Smith, 1998; Kutner, Nachtsheim, \& Neter, 2003). This method is more parsimonious than methods that perform all possible subset regressions and then select the "best" model, which has the maximum value of $R^{2}$. In forward selection with review, the modeling process starts by computing the mean of the response variable and then finding the predictor that, if included in the model, has the smallest $p$ value. This variable is included, along with the mean of the response variable, as the first-step model. The next variable added to the model is the predictor with the smallest $p$ value relative to the residuals from Step 1. Because of partial correlations between the two predictor variables, the $p$ values might require revision. If the $p$ values remain statistically significant, the second step of the process is complete. However, if one of the $p$ values becomes nonsignificant, this variable is deleted from the model.

This process of forward selection with review continues until all of the variables in the model have $p$ values that are statistically significant and all of the variables not in the model have $p$ values that are not statistically significant. The final regression is considered the "best" model that explains the maximum amount of variation in the response variable. Our statistical software was Excel for the descriptive analyses and S-Plus Version 8.0 for the regressions.

We used the QLQ-C30 scales in the regression analyses in two different ways. We used the Emotional Functioning Scale as a dependent measure because the purpose of the study was to elucidate factors associated with individual differences in psychological adjustment. We used the other QLQ-C30 
scales as predictor variables because they provided indices of the subjectively rated severity of the patient's cancer symptoms and degree of functional impairment attributable to the disease and side effects of its treatment. We included these indices in the regressions to account for some of the variance in emotional outcomes attributable to disease severity, so the psychosocial variables of interest would have an opportunity to demonstrate associations with the remaining variance in emotional outcomes. Without some strategy for accounting for individual differences in illness severity, it seemed possible that this factor would obscure relationships between psychosocial variables and emotional outcomes. This strategy seemed especially important because our sample was heterogenous in type and severity of cancer.

\section{RESULTS}

In the presentation below, the text includes mention of all predictor variables that met a significance criterion of $p<.05$. The text does not mention predictor variables with $p$ values between .05 and .10 unless these nonsignificant trends mirror significant findings. Readers are referred to the tables for information on marginally significant regression coefficients, which contributed to the overall regressions even if they did not represent reliable relationships in and of themselves.

The multiple regression for HADS Anxiety scores is presented in Table 2. For the complete regression, $F(12,177)=24.75, \mathrm{p}<.0001$, and multiple $R^{2}=.626$. Anxiety was related to ethnic group, $t(177)=-2.04, \mathrm{p}=.043$, with Whites producing higher scores than African American participants. Two scores from the QLQ-C30 emerged as significant: High levels of anxiety were associated with low scores on cognitive functioning, $t=-3.52, p=.0005$, and high scores on insomnia, $t=4.06, p=.0001$. Anxiety was inversely

TABLE 2 Multiple Regression for Anxiety Scores

\begin{tabular}{lrrr}
\hline Coefficient & Value & Standard Error & $p$ \\
\hline Intercept) & 14.72 & 2.29 & $<.001$ \\
Ethnic group & -1.14 & .56 & .043 \\
Recurrence & 1.01 & .56 & .076 \\
Behavioral disengagement & .45 & .24 & .073 \\
Venting & .33 & .17 & .054 \\
Instrumental support & .66 & .18 & $<.001$ \\
Self-blame & .75 & .17 & $<.001$ \\
Planning & .31 & .15 & .048 \\
Humor & -.30 & .13 & .021 \\
Acceptance & -.80 & .20 & $<.001$ \\
Cognitive functioning & -.04 & .01 & $<.001$ \\
Insomnia & .03 & .01 & $<.001$ \\
Social receptivity & -.20 & .09 & .035 \\
\hline
\end{tabular}


TABLE 3 Multiple Regression for Depression Scores

\begin{tabular}{lrcrr}
\hline Coefficient & Value & Standard Error & $t$ & \multicolumn{1}{c}{$p$} \\
\hline (Intercept) & 22.39 & 1.57 & 14.28 & $<.001$ \\
Behavioral disengagement & .79 & .16 & 4.92 & $<.001$ \\
Venting & .20 & .11 & 1.85 & .066 \\
Self-blame & .25 & .11 & 2.19 & .030 \\
Humor & -.29 & .09 & -3.27 & .001 \\
Acceptance & -.33 & .13 & -2.60 & .010 \\
Religion & .22 & .08 & 2.61 & .010 \\
Physical functioning & -.03 & .01 & -4.17 & $<.001$ \\
Cognitive functioning & -.02 & .01 & -3.36 & $<.001$ \\
Social functioning & -.02 & .01 & -3.01 & .003 \\
Appetite loss & .01 & .01 & 2.20 & .029 \\
Benefit finding & -.15 & .04 & -4.18 & $<.001$ \\
Hope & -.15 & .04 & -3.67 & $<.001$ \\
\hline
\end{tabular}

related to social receptivity, $t=-2.13, p=.035$. Significant results were obtained for a number of coping strategies measured by the Brief COPE. Anxiety was positively related to self-blame, $t=4.52$, $p<.0001$; instrumental support, $t=3.63, p=.0004$; and planning, $t=1.99, p=.048$. Anxiety was negatively related to humor, $t=-2.33, p=.021$; and acceptance, $t=-4.01$, $p=.0001$.

Table 3 presents the multiple regression for HADS Depression scores. For the complete regression, $F(13,234)=39.33, p<.0001$, and multiple $R^{2}=.686$. There were significant findings for several QLQ-C30 scales. Depression was negatively related to physical functioning, $t=-4.17, p<.0001$; cognitive functioning, $t=-3.36, p=.001$; and social functioning, $t=-3.01$, $p=.003$. Depression was positively related to insomnia, $t=2.81$, and appetite loss, $t=2.20, p=.03$. Relationships between depression and COPE scores were largely similar to the results for HADS anxiety scores. High levels of depression were associated with the coping strategy of behavioral disengagement, $t=4.92, p<.0001$, which also showed a marginally significant association with anxiety. High levels of depression were associated with self-blame, $t=2.19, p=.030$; and religion, $t=2.61, p=.010$. Low levels of depression were associated with acceptance, $t=-2.60, p=.010$; and humor, $t=-3.27, p=.001$. Depression was negatively related to hope scores, $t=-3.67, p=.0003$. Finally, low depression scores were associated with high levels of benefit finding, $t=-4.19, p<.0001$.

The regression for QLQ-C30 Emotional Functioning is presented in Table 4. For the overall regression, $F(13,184)=28.49, p<.0001$, and multiple $R^{2}=.692$. Emotional functioning scores were higher in African American than White participants, $t(184)=3.09, p=.002$. Emotional functioning was related to three other QLQ-C30 Functioning scales: There were positive associations with cognitive functioning, $t=3.38, p=.001$, and social functioning, $t=2.63, p=.009$; unexpectedly, there was an inverse 
TABLE 4 Multiple Regression for Emotional Functioning Scores

\begin{tabular}{lrcrr}
\hline Coefficient & Value & Standard Error & $t$ & \multicolumn{1}{c}{$p$} \\
\hline (Intercept) & 35.28 & 9.80 & 3.60 & $<.001$ \\
Ethnic group & 8.18 & 2.64 & 3.10 & .002 \\
Self-distraction & -1.10 & .64 & -1.71 & .090 \\
Behavioral disengagement & -2.74 & 1.12 & -2.45 & .015 \\
Venting & -3.21 & .81 & -3.97 & $<.001$ \\
Self-blame & -3.13 & .76 & -4.11 & $<.001$ \\
Acceptance & 2.28 & .99 & 2.29 & .023 \\
Emotional processing & -.92 & .45 & -2.04 & .042 \\
Emotional expression & 1.23 & .54 & 2.28 & .024 \\
Role functioning & -.08 & .03 & -2.41 & .017 \\
Cognitive functioning & .17 & .05 & 3.38 & .001 \\
Social functioning & .12 & .05 & 2.63 & .010 \\
Nausea/vomiting & .11 & .05 & 2.09 & .038 \\
Insomnia & -.17 & .04 & -4.61 & $<.001$ \\
\hline
\end{tabular}

association with role functioning, $t=-2.41, p=.017$. Emotional functioning was negatively associated with the QLQ-C30 Symptom scale measuring insomnia, $t=-4.61, \mathrm{p}<.0001$; unexpectedly, it was positively associated with nausea/vomiting, $t=2.09, p=.038$. Several COPE variables demonstrated relationships with emotional functioning. Worse functioning was associated with use of three of these coping mechanisms: behavioral disengagement, $t=-2.45, p=.018$; venting, $t=-3.97, p=.0001$; and self-blame, $t=$ $-4.11, p=.0001$. One coping strategy, acceptance, was associated with high emotional functioning scores, $t=2.29, p=.023$. Emotional functioning was inversely related to scores on the emotional processing measure, $t=-2.04$, $p=.042$, and was positively related to scores on the Emotional Expression measure, $t=2.28, p=.024$.

The regression for happiness scores is presented in Table 5. For the full regression, $F(10,220)=25.22, p<.0001$, and multiple $R^{2}=.534$. Like the regressions for the measures of dysphoric emotion, the regression

TABLE 5 Multiple Regression for Happiness Scores

\begin{tabular}{|c|c|c|c|c|}
\hline Coefficient & Value & Standard Error & $t$ & $p$ \\
\hline (Intercept) & -1.46 & 1.15 & -1.27 & .207 \\
\hline Ethnic group & .85 & .28 & 3.00 & .003 \\
\hline Active coping & .21 & .08 & 2.47 & .014 \\
\hline Behavioral disengagement & -.64 & .13 & -5.00 & $<.001$ \\
\hline Planning & -.27 & .08 & -3.44 & .001 \\
\hline Humor & .22 & .07 & 3.38 & .001 \\
\hline Acceptance & .29 & .10 & 2.96 & .003 \\
\hline Cognitive functioning & .02 & .01 & 3.29 & .001 \\
\hline Insomnia & -.01 & .01 & -2.41 & .017 \\
\hline Social receptivity & .12 & .05 & 2.70 & .008 \\
\hline Hope & .13 & .03 & 4.22 & $<.001$ \\
\hline
\end{tabular}


TABLE 6 Multiple Regression for Positive Affect Scores

\begin{tabular}{lcccr}
\hline Coefficient & Value & Standard Error & $t$ & \multicolumn{1}{c}{$p$} \\
\hline (Intercept) & 2.91 & 1.63 & 1.78 & .076 \\
Age & .02 & .01 & 1.92 & .056 \\
Behavioral disengagement & -.66 & .12 & -5.61 & $<.001$ \\
Self-blame & -.20 & .08 & -2.45 & .016 \\
Humor & .15 & .07 & 2.24 & .026 \\
Acceptance & .49 & .10 & 4.81 & $<.001$ \\
Emotional processing & -.14 & .05 & -2.96 & .003 \\
Physical functioning & .02 & .01 & 3.02 & .003 \\
Cognitive functioning & .01 & .01 & 2.90 & .004 \\
Nausea/vomiting & .01 & .01 & 2.68 & .008 \\
Benefit finding & .11 & .02 & 4.72 & $<.001$ \\
Social receptivity & .18 & .05 & 3.72 & $<.001$ \\
Hope & .10 & .03 & 3.23 & .001 \\
Chemotherapy & -.38 & .22 & -1.75 & .082 \\
\hline
\end{tabular}

for happiness indicated better adjustment in African American participants, compared to Whites, $t(220)=3.00, p=.003$. Happiness scores were related to two subscales of the QLQ-C30; there was a positive association with cognitive functioning, $t=3.29, p=.001$, and a negative association with insomnia, $t=-2.41, p=.017$. There were a number of significant results for the COPE scales. Low levels of happiness were associated with use of behavioral disengagement, $t=-5.00, p<.0001$, and planning, $t=-3.44$, $p=.001$. High levels of happiness were related to use of active coping, $t=$ 2.47, $p=.014$; humor, $t=3.38, p=.001$; and acceptance, $t=2.96, p=$ .003. Happiness was positively associated with social receptivity, $t=2.70$, $p=.008$. Happiness was also positively related to scores on the Hope Scale, $t=4.22, p<.0001$.

Table 6 presents the regression for the set of four positive affect items drawn from the CESD. For the complete regression, $F(13,217)=37.20$, $p<.0001$, and multiple $R^{2}=.690$. On the QLQ-C30, our measure of positive affect was directly related to physical functioning, $t(217)=3.02, p=.003$; and cognitive functioning, $t=2.90, p=.004$. Unexpectedly, positive affect was associated with high scores on the nausea/vomiting symptom scale, $t=2.68, p=.008$. On the COPE, positive affect was inversely related to behavioral disengagement, $t=-5.61, p<.0001$; and self-blame, $t=-2.45$, $p=.015$. Positive affect was associated with use of humor, $t=2.24, p=$ .026 ; and acceptance, $t=4.81, p<.0001$. Scores on the Emotional Processing Scale were inversely related to positive affect, $t=-2.96, p=.003$. Positive affect was associated with high levels of social receptivity, $t=3.72, p=$ .0003 ; high scores on the Hope Scale, $t=3.23, p=.001$; and high levels of benefit finding, $t=4.72, p<.0001$.

Table 7 presents a summary, in schematic form, of the results for all the psychosocial variables. To offer a simple, clear picture of the overall 


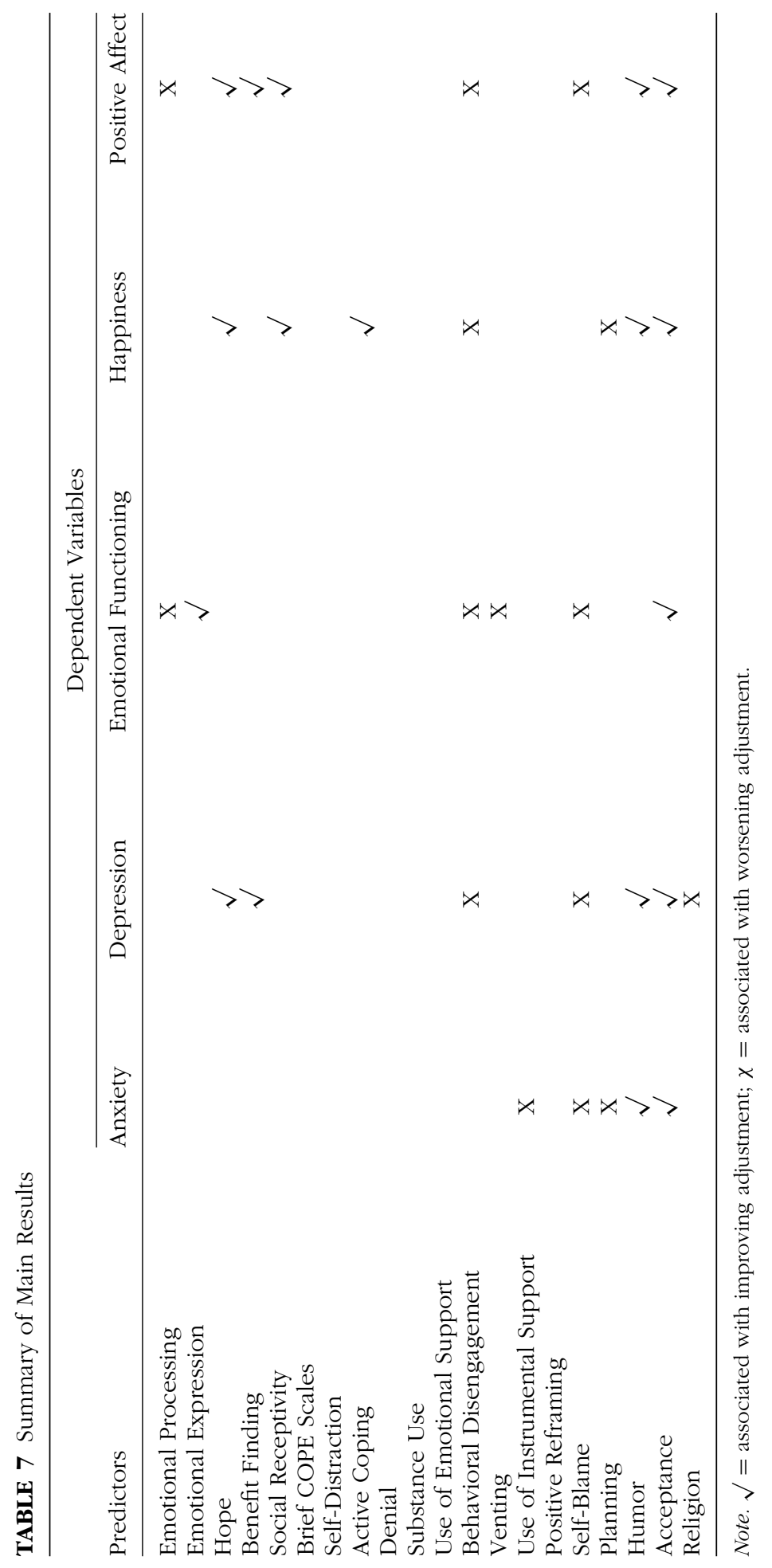


pattern of findings, the table does not present numerical results, and it uses symbols to convey whether a variable was associated with better or worse functioning, thus making it unnecessary for readers to keep track of scoring direction for the various measures.

\section{DISCUSSION}

Our study examined four broad classes of variables as predictors of emotional outcomes in cancer patients: Demographic characteristics, medical variables, subjective ratings of illness effects (the QLQ-C30), and copingrelated variables. Overall, demographic and medical variables showed few relationships with emotional outcomes, whereas subjective ratings of illness effects and coping-related variables demonstrated many associations with adjustment.

\section{Methodological Limitations}

One limitation of the study pertains to our sample, which consisted of voluntary participants in a community support organization for people with cancer. We do not know whether cancer patients who choose to avail themselves of such services are representative of all patients with this illness. Therefore, it is unknown to what degree the results of the current study would generalize to cancer patients as a whole. It should be noted, however, that patients who seek services are a subgroup of particular interest to practitioners, because these are the patients whom we have opportunities to help. The present results are clearly applicable to this subpopulation and, therefore, may be useful in the design of psychosocial interventions.

Because our design was correlational rather than experimental, the results do not demonstrate causal relationships. Our findings indicate which variables were associated with differences in adjustment, but we do not know whether the predictor variables caused the emotional outcomes. In particular, though our results indicate which coping strategies were associated with more and less successful adjustment, we cannot infer that use of the strategies caused the differences in outcomes. It is also possible that different emotional states cause different coping strategies to be used, and that some third category of variable influences emotional outcomes and coping strategies.

\section{Demographics, Medical Variables, and Subjective Illness Ratings}

We found no significant relationships between our measures of emotional functioning and the variables of age, gender, and education. These results are consistent with those of past studies, including a meta-analysis by van't Spijker et al. (1997), which noted inconsistent relationships between 
demographic variables and psychosocial outcomes in cancer patients. However, we found that African American participants showed more positive adjustment than Whites on three of five dependent measures. Descriptions of African American culture emphasize large support networks based in extended family ties (Hildebrand, Phenice, Gray, \& Hines, 1996; McCollum, 1997); perhaps this strong source of support buffers African American patients against the stress of having cancer.

Objective medical variables did not demonstrate relationships with emotional outcomes. These results, too, are similar to the results of van't Spijker et al.'s (1997) meta-analysis, which found that medical variables such as disease stage and even recurrence did not show consistent associations with psychosocial outcomes in people with cancer. In contrast, scores on the QLQ-C30 Functioning and Symptom scales demonstrated many significant relationships with emotional outcomes. In past studies, too, subjective ratings of illness severity have proved to be more reliable predictors of emotional distress, compared to objective medical variables (Lethborg et al., 2007; Manne et al., 2001; and see meta-analysis by van't Spijker et al., 1997).

\section{Coping Strategies}

Our results indicated numerous associations between psychosocial variables and adjustment in our sample of people with cancer. Many of the scales of the Brief COPE (Carver, 1997) exhibited such associations. As summarized in Table 7 , the results included some consistent patterns that suggest which coping strategies are associated with better and worse adjustment in this population.

In four of five regressions, patients who used humor as a coping strategy exhibited low levels of dysphoric emotion and high levels of positive emotion, compared to patients who made little or no use of humor. The COPE items making up this scale do not merely depict a generally ironic, lighthearted, or humorous attitude toward life; the items depict humor specifically about having cancer, for example: "I've been making fun of the situation," and "I've been making jokes about it." Carver et al. (1993), too, found that use of humor as a coping mechanism was associated with good adjustment in cancer patients.

There was consistent evidence that two coping strategies, behavioral disengagement and self-blame, were associated with poor adjustment. In four of five regressions for each variable, disengagement and self-blame were associated with high levels of negative affect and low levels of positive emotion. These findings are consistent with past research on these coping processes in cancer patients (Perczek, Burke, Carver, Krongraad, \& Terris, 2002; Ptacek, Pierce, Ptacek, \& Nogel, 1999).

From a "scorecard" perspective, the coping strategy of acceptance emerged as the winner in the current study, demonstrating associations with 
better adjustment on all five of our dependent measures. The finding is made more striking by a resemblance between the coping mechanisms of acceptance and disengagement, which showed opposite relationships with adjustment even though both involve relinquishing the goal of changing the concrete situation. The difference beneath the similarity becomes apparent when the acceptance items are considered: "I've been accepting the reality of the fact that it has happened," and "I've been learning to live with it." These items do not express hopelessness about coping with cancer as a life challenge, which is the type of giving up depicted by the disengagement items. Carver et al. (1993), Stanton et al. (2002), and Lutgendorf et al. (2002) also found that use of acceptance as a coping mechanism was associated with positive adjustment in cancer patients.

Past research on coping with cancer has devoted extensive attention to the distinction between passive-avoidant coping styles and active, problemfocused styles. Our results for the Brief COPE suggest that the active/passive distinction is too broad to be of much use in identifying more and less effective coping strategies, and that the more important distinctions lie within these two general categories. For example, among the COPE strategies that would be considered passive, behavioral disengagement was negatively related to well-being, but acceptance and humor were positively related to adjustment.

\section{Other Coping-Related Variables}

We found that emotional processing - that is, thinking about cancer-related issues-was associated with more distress and less positive emotion on some measures. We obtained an isolated finding suggesting that expressing emotions to others is negatively related to dysphoric emotion. Research on emotional expression and processing in cancer patients by Stanton and her colleagues has produced complex results suggesting that the effects of these variables depend on interactions with each other, gender, stress level, and social support (Low et al., 2006; Stanton et al., 2000).

In contrast to past studies (Crothers et al., 2005; Helgeson et al., 2004; Schnoll et al., 2002), our measure of social support did not demonstrate relationships with emotional distress, although Social Receptivity scores were related to our two measures of positive emotion. The difference from past findings might have occurred because our instrument focused on one specific aspect of support, namely, the social network's receptivity to talking about cancer experiences.

Our results for benefit finding were consistent with past research, as summarized by Helgeson et al.'s (2006) meta-analysis. We and they found that benefit finding was associated with less depression and more positive affect while being unrelated to anxiety and overall emotional distress. In 
past research on benefit finding, results have varied as a function of specific measure (Lechner et al., 2006; Sears et al., 2003), but our replication of Helgeson et al.'s meta-analytic result suggests that benefit finding shows consistent, though contrasting, relationships with different types of emotional outcomes.

In our sample, high levels of hope were associated with low depression and high levels of happiness and positive affect. These results contrast with Stanton et al.'s (2002) study of cancer patients, which did not find relationships between hope and variables like these.

\section{IMPLICATIONS FOR PRACTICE}

Although the current study produced a complex array of results, there were some general themes supported by consistent findings, and these themes have implications for intervention with cancer patients. In regard to coping strategies, the results suggest that therapists could help patients by encouraging them to accept the reality of their illness and to focus their efforts on coping with its effects on their lives. Self-blame should be discouraged. It might be useful for psychosocial interventions to include humor and to guide participants' use of this coping strategy. Obviously, this should be done with the utmost sensitivity. We obtained less consistent but significant evidence that would support therapeutic efforts to strengthen a general attitude of hopefulness and to identify benefits among the difficult, painful consequences of cancer.

\section{REFERENCES}

Aaronson, N. K., Ahmedzai, S., Bergman, B., Bullinger, M., Cull, A., Duez, N. J., et al. (1993). The European Organization for Research and Treatment of Cancer QLQ-C30: A quality-of-life instrument for use in international clinical trials in oncology. Journal of the National Cancer Institute, 85, 365-376.

Antoni, M. H., Lehman, J. M., Kilbourn, K. M., Boyers, A. E., Culver, J. L., Alferi, S. M., et al. (2001). Cognitive-behavioral stress management intervention decreases the prevalence of depression and enhances benefit finding among women under treatment for early-stage breast cancer. Health Psychology, 20, 20-32.

Bardwell, W. A., Nataragan, L., Dimsdale, J. E., Rock, C. L., Mortimer, J. E., Hollenbach, K., et al. (2006). Objective cancer-related variables are not associated with depressive symptoms in women treated for early-stage breast cancer. Journal of Clinical Oncology, 24, 2420-2427.

Barnum, D. D., Snyder, C. R., Rapoff, M. A., Mani, M. M., \& Thompson, R. (1998). Hope and social support in the psychological adjustment of pediatric burn survivors and matched controls. Children's Health Care, 27, 15-30.

Bjelland, I., Dahl, A. A., Haug, T. T., \& Neckelmann, D. (2002). The validity of the Hospital Anxiety and Depression Scale: An updated literature review. Journal of Psychosomatic Research, 52, 69-77. 
Carlson, L. E., Angen, M., Cullum, J., Goodey, E., Koopmans, J., Lamont, L., et al. (2004). High levels of untreated distress and fatigue in cancer patients. British Journal of Cancer, 90, 2297-2304.

Carver, C. S. (1997). You want to measure coping but your protocol's too long: Consider the brief COPE. International Journal of Behavioral Medicine, 4, 92-100.

Carver, C. S., \& Antoni, M. H. (2004). Finding benefit in breast cancer during the year after diagnosis predicts better adjustment 5 to 8 years after diagnosis. Health Psychology, 23, 595-598.

Carver, C. S., Pozo, C., Harris, S. D., Noriega, V., Scheier, M. F., Robinson, D. W., et al. (1993). How coping mediates the effect of optimism on distress: A study of women with early stage breast cancer. Journal of Personality and Social Psychology, 65, 375-390.

Carver, C. S., Scheier, M. F., \& Weintraub, J. K. (1989). Assessing coping strategies: A theoretically based approach. Journal of Personality and Social Psychology, 56, 267-283.

Carver, C. S., Smith, R. G., Antoni, M. H., Petronis, V. M., Weiss, S., \& Derhagopian, R. P. (2005). Optimistic personality and psychosocial well-being during treatment predict psychosocial well-being among long-term survivors of breast cancer. Health Psychology, 24, 508-516.

Chan, C. L. W., Ho, R. T. H., Lee, P. W. H., Cheng, J. Y. Y., Leung, P. P. Y., Foo, W., et al. (2006). A randomized controlled trial of psychosocial interventions using the psychophysiological framework for Chinese breast cancer patients. Journal of Psychosocial Oncology, 24, 3-26.

Ciaramella, A., \& Poli, P. (2001). Assessment of depression among cancer patients: The role of pain, cancer type, and treatment. Psycho-Oncology, 10, 156-165.

Constanzo, E. S., Lutgendorf, S. K., Rothrock, N. E., \& Anderson, B. (2006). Coping and quality of life among women extensively treated for gynecologic cancer. Psycho-Oncology, 15, 132-142.

Crothers, M. K., Tomter, H. D., \& Garske, J. P. (2005). The relationships between satisfaction with social support, affect balance, and hope in cancer patients. Journal of Psychosocial Oncology, 23, 103-118.

Draper, N. R., \& Smith H. (1998). Applied regression analysis. New York: John Wiley and Sons.

Elliott, T. R., Witty, S., Herrick, S., \& Hoffman, J. T. (1991). Negotiating reality after physical loss: Hope, depression, and disability. Journal of Personality and Social Psychology, 61, 608-613.

Epping-Jordan, J. E., Compas, B. E., Osowiecki, D. M., Oppedisano, G., Gerhardt, C., Primo, K., et al. (1999). Psychological adjustment in breast cancer: Processes of emotional distress. Health Psychology, 18, 315-326.

Fordyce, M. W. (1988). A review of research on the happiness measures: A sixty second index of happiness and mental health. Social Indicators Research, 20, 355-381.

Gall, T. L., Miguez de Renart, R. M., \& Boonstra, B. (2000). Religious resources in long-term adjustment to breast cancer. Journal of Psychosocial Oncology, 18, 21-37.

Glanz, K., \& Lerman, C. (1998). Psychosocial impact of breast cancer: A critical review. Annals of Behavioral Medicine, 14, 204-212. 
Hack, T., \& Degner, L. F. (2004). Coping responses following breast cancer diagnosis predict psychological adjustment three years later. Psycho-Oncology, 13, $235-247$.

Hann, D., Winter, K., \& Jacobsen, P. (1999). Measurement of depressive symptoms in cancer patients: Evaluation of the Center for Epidemiological Studies Depression Scale (CES-D). Journal of Psychosomatic Research, 46, 437-443.

Helgeson, V. S., Cohen, S., Schulz, R., \& Yasko, J. (2000). Group support interventions for women with breast cancer: Who benefits from what? Health Psychology, 19, 107-114.

Helgeson, V. S., Reynolds, K. A., \& Tomich, P. L. (2006). A meta-analytic review of benefit finding and growth. Journal of Consulting and Clinical Psychology, 74, 797-816.

Helgeson, V. S., Snyder, P., \& Seltman, H. (2004). Psychological and physical adjustment to breast cancer over 4 years: Identifying distinct trajectories of change. Health Psychology, 23, 3-15.

Herrmann, C. (1997). International experiences with the Hospital Anxiety and Depression Scale-a review of validation data and clinical results. Journal of Psychosomatic Research, 42, 17-41.

Hildebrand, V., Phenice, L. A., Gray, M. M., \& Hines, R. P. (1996). Knowing and serving diverse families. Englewood Cliffs, NJ: Prentice Hall.

Kart, C. S., \& Ford, M. E. (2002). Exploring the factorial structure of the EORTC QLQC30: Racial differences in measuring health-related quality of life in a sample of urban, older adults. Journal of Aging and Health, 14, 399-421.

Komblith, A. B., Powell, M., Regan, M. M., Bennett, S., Krasner, C., Moy, B., et al. (2007). Long-term psychosocial adjustment of older vs younger survivors of breast and endometrial cancer. Psycho-Oncology, 16, 895-903.

Kugaya, A., Akechi, T., Okamura, H., Mikami, I., \& Uchitomi, Y. (1999). Correlates of depressed mood in ambulatory head and neck cancer patients. PsychoOncology, 8, 494-499.

Kutner, M. H., Nachtsheim, C. J., \& Neter, J. (2003). Applied linear regression models. New York: McGraw Hill/Irwin.

Lechner, S. C., Carver, C. S., Antoni, M. H., Weaver, K. E., \& Phillips, K. M. (2006). Curvilinear associations between benefit finding and psychosocial adjustment to breast cancer. Journal of Consulting and Clinical Psychology, 74, 828-840.

Lethborg, C., Aranda, S., Cox, S., \& Kissane, D. (2007). To what extent does meaning mediate adaptation to cancer? The relationship between physical suffering, meaning in life, and connection to others in adjustment to cancer. Palliative and Supportive Care, 5, 377-388.

Low, C. A., Stanton, A. L., Thompson, N., Kwan, L., \& Ganz, P. A. (2006). Contextual life stress and coping strategies as predictors of adjustment to breast cancer survivorship. Annals of Behavioral Medicine, 32, 235-244.

Lutgendorf, S. K., Anderson, B., Ullrich, P., Johnsen, E. L., Buller, R. E., Sood, A. K., et al. (2002). Quality of life and mood in women with gynecologic cancer: a one year prospective study. Cancer, 94, 131-140.

Manne, S., Glassman, M., \& Du Hamel, K. (2001). Intrusion, avoidance, and psychological distress among individuals with cancer. Psychosomatic Medicine, 63, 658-667. 
McCollum, V. J. C. (1997). Evolution of the African American family personality: Considerations for family therapy. Journal of Multicultural Counseling and Development, 25, 219-229.

McGovern, R. J., Heyman, E. N., \& Resnick, M. I. (2002). An examination of coping style and quality of life of cancer patients who attend a prostate cancer support group. Journal of Psychosocial Oncology, 20, 57-68.

Mermelstein, H. T., \& Lesko, L. (1992). Depression in patients with cancer. PsychoOncology, 1, 199-125.

Mosher, C. E., \& Danoff-Burg, S. (2005). A review of age differences in psychological adjustment to breast cancer. Journal of Psychosocial Oncology, 23, 101-114.

Osborne, R. H., Elsworth, G. R., \& Hopper, J. L. (2003). Age-specific norms and determinants of anxiety and depression in 731 women with breast cancer recruited through a population-based cancer registry. European Journal of Cancer, 39, $755-762$.

Osowiecki, D., \& Compas, B. E. (1998). Psychological adjustment to cancer: Control beliefs and coping in adult cancer patients. Cognitive Therapy and Research, 22, 483-499.

Parker, P. A., Baile, W. F., De Moor, C., \& Cohen, L. (2003). Psychosocial and demographic predictors of quality of life in a large sample of cancer patients. Psycho-Oncology, 12, 183-193.

Perczek, R. E., Burke, M. A., Carver, C. S., Krongraad, A., \& Terris, M. K. (2002). Facing a prostate cancer diagnosis: Who is at risk for increased distress? Cancer, 94, 2923-2929.

Ptacek, J. T., Pierce, G. R., Ptacek, J. J., \& Nogel, C. (1999). Stress and coping processes in men with prostate cancer: The divergent views of husbands and wives. Journal of Social and Clinical Psychology, 18, 299-324.

Radloff, L. S. (1977). The CES-D scale: A self-report depression scale for research in the general population. Applied Psychological Measurement, 1, 385-401.

Rodrigue, J. R., Behen, J. M., \& Tumlin, T. (1994). Multidimensional determinants of psychological adjustment to cancer. Psycho-Oncology, 3, 205-214.

Roesch, S. C., Adams, L., Hines, A., Palmores, A., Vyas, P., Tran, C., et al. (2005). Coping with prostate cancer: A meta-analytic review. Journal of Behavioral Medicine, 28, 281-293.

Schag, C. A., Ganz, P. A., Wing, D. S., Sim, M. S., \& Lee, J. J. (1994). Quality of life in adult survivors of lung, colon, and prostate cancer. Quality of Life Research, 3, 127-141.

Schnoll, R. A., Knowles, J. C., \& Harlow, L. (2002). Correlates of adjustment among cancer survivors. Journal of Psychosocial Oncology, 20, 37-59.

Sears, S. R., Stanton, A. L., \& Danoff-Burg, S. (2003). The yellow brick road and the emerald city: Benefit finding, positive reappraisal coping, and posttraumatic growth in women with early-stage breast cancer. Health Psychology, 22, 487-497.

Shapiro, S. L., Lopez, A. M., Schwartz, G. W., Bootzin, R. Figueredo, A. J., Braden, C. J., et al. (2001). Quality of life and breast cancer: Relationship to psychosocial variables. Journal of Clinical Psychology, 57, 501-519.

Snyder, C. R., Harris, C., Anderson, J. R., Holleran, S. A., Irving, L. M., Sigmon, S. T., et al. (1991). The will and the ways: Development and validation of 
an individual-differences measure of hope. Journal of Personality and Social Psychology, 60, 570-585.

Stanton, A. L., Danoff-Burg, S., \& Huggins, M. E. (2002). The first year after breast cancer diagnosis: Hope and coping strategies as predictors of adjustment. PsychoOncology, 11, 93-102.

Stanton, A. L., Kirk, S. B., Cameron, C. L., \& Danoff-Burg, S. (2000). Coping through emotional approach: Scale construction and validation. Journal of Personality and Social Psychology, 78, 1150-1169.

Tartaro, J., Roberts, J., Nosarti, C., Crayford, T., Luecken, L., \& David, A. (2005). Who benefits? Distress, adjustment and benefit-finding among breast cancer survivors. Journal of Psychosocial Oncology, 23, 45-64.

Thune-Boyle, I. C., Stygall, J. A., Keshtgar, M. R., \& Newman, S. P. (2005). Do religious/spiritual strategies affect illness adjustment in patients with cancer? A systematic review of the literature. Social Science and Medicine, 63, 151-164.

Tomich, P. L., \& Helgeson, V. S. (2004). Is finding something good in the bad always good? Benefit finding among women with breast cancer. Health Psychology, 23, $16-23$.

van't Spijker, A., Trijsburg, R. W., \& Duivenvoorden, H. J. (1997). Psychological sequelae of cancer diagnosis: A meta-analytical review of 58 studies after 1980. Psychosomatic Medicine, 59, 280-293.

Voogt, E., Van Der Heide, L., Van Leeuwen, A. F., Visser, A. P., Cleiren, M. P. H. D., Passchier, J., et al. (2005). Positive and negative affect after diagnosis of advanced cancer. Psycho-Oncology, 14, 262-273.

Waldmann, A., Fritzkuleit, R., Raspe, H., \& Katalinic, A. (2007). The OVIS study: Health related quality of life measured by the EORTC QLQ-C30 and -BR23 in German female patients with breast cancer from Schleswig-Holstein. Quality of Life Research, 16, 767-776.

Watson, D., Clark, L. A., \& Tellegen, A. (1988). Development and validation of brief measures of positive and negative affect: The PANAS scales. Journal of Personality and Social Psychology, 54, 1063-1070.

Zabora, J. R., Brintzenhofeszoc, K., Jacobsen, P., Curbow, B., Piantadosi, S., Hooker, C., et al. (2001). A new psychosocial screening instrument for use with cancer patients. Psychosomatics, 42, 241-246.

Zelenski, J. M., \& Larsen, R. J. (1999). Susceptibility to affect: A comparison of three personality taxonomies. Journal of Personality, 67, 761-791.

Zigmond, A. S., \& Snaith, R. P. (1983). The Hospital Anxiety and Depression Scale. Acta Psychiatrica Scandinavia, 67, 361-370. 